\title{
Electric Power Industry Accident Prevention in Canada
}

\author{
Ganesh Narine
}

\begin{abstract}
The Canadian electric power industry is a sophisticated first-world system that forms integral and critical ties on the North American electric power grid. The availability of safe, reliable, high-quality electric power is vitally important for customers in Canada, a country with extreme variations in environmental conditions and geographical reach. The purpose of this study is to prevent accidents where Canadian electric power industry workers become seriously or fatally injured. The study, conducted on Survey Monkey and facilitated over a four-round Delphi exercise, involved nine participants who were a panel from the Canadian electric power industry. The participants provided feasible, desirable, important solutions that they were confident will or can prevent future workplace accidents and at the same time, serious or fatal injuries to workers. Participants in this study provide twenty different solutions.
\end{abstract}

Index Terms - working experiences, electric power industry, prevent future workplace accidents.

\section{INTRODUCTION}

Moshansky (1992) investigated a 1989 airline crash at Dryden, Ontario, in which 24 persons died and indicated, "Modern air transportation is a complex enterprise. Similarly complex, are the causes of aircraft accidents. Previous aircraft accident investigations have demonstrated that an accident or serious incident normally is not due to a single cause, but the cumulative result of oversights, shortcuts, and miscues which, considered in isolation, might have had minimal causal significance" (p.5). That perspective resonates in the electricity industry experience on workplace accidents, serious worker injuries, and death. In 1992, an airline out of New York crashed, and 27 persons died. In that accident, investigators found significant contributing factors similar to what Moshansky found in the Dryden crash (NTSB, 1993). De-icing of the aircraft was deemed, in each instance, as a significant contributor to the accident. Even more incredible is that a 1985 aircraft disaster in Newfoundland preceded the Dryden accident, Canada, where 256 persons died. The Canadian Aviation Safety Board (CASB, 1992), indicated that the probable cause of the 1985 accident was that the plane was not de-iced.

Organizational culture improves when accidents and disaster learning from one industry extended to another and contributed to a reduction of near misses and accident prevention (Labib, 2015; Murata, 2017). Patton (2018) and McCabe (2019) described how Canadian electric industry workers were killed while cutting trees in separate accidents. Cashman (2019) described an accident where a utility company employee in the United States died while

Ganesh Narine, Ph.D., MPhil, MSc (Eng), BSc (Eng), is an electric industry engineer and manager with more than 30 years of experience in Generation, Transmission, Distribution, Engineering, Management, and Executive Management in the Caribbean (Trinidad and Tobago). performing tree cutting work. TSB (2017) recounted how four power line workers died in a helicopter accident in Canada. In the United States, two individuals died in a helicopter accident while conducting work in New York State (NTSB, 2018). Opportunities to prevent serious-injury or fatal workplace accidents exist in the electric power industry. This work, consistent with a previous study by Narine (2019), represents an attempt to learn from workplace accidents and to use lessons from these accidents to prevent further and future accidents. The electric power industry is sophisticated and complex. Safety management systems are designed and referenced against the stringent technical, industry, and regulatory standards (Manuele, 2014). Professionals are hired specifically to monitor and report on organizational safety performance. Despite these elaborate arrangements, accidents, where workers become seriously injured or killed at work, continue to happen (Volberg, 2017).

\section{BACKGROUND}

Workplace safety is challenging and unmanageable if individual responsibilities and roles and organizational duties and responsibilities are not clearly established or uniformly practiced. Workers in the electric power industry undergo a set training schedule designed against industry standards, legislation, and organizational safety policies, rules, and procedures. Learning also occurs through a graduated scheme by exposing workers to progressively challenging work situations and tasks, supervised by individuals who are specially trained and experienced in managing trainees in actual work settings. Aboagye-Nimo, Raiden, King, and Tietze (2015) posited that individuals learn and develop work knowledge from exercises where they practice activities while being guided by other workers performing the task. Laberge, MacEachen, and Calvet (2014) suggested that workers become amenable to organizational change when learning occurs on the job, and it is inclusive and tolerable. That way, workers develop individual and group knowledge, become experienced and communicate with other individuals at work in ways that lend to improved morale and motivation. Managers and supervisors can positively influence accident prevention and safe work by encouraging workers to report near misses (Probst, 2015). Organizational leaders who actively focus on safety as a top priority and can realize genuine support from fellow executives and management to influence worker safety belief, superior organization performance, and accident prevention (Tucker, Ogunfowora, \& Ehr, 2016).

\section{RESEARCH QUESTION AND CONCEPTUAL FRAMEWORK}

What do Canadian electrical power industry experts regard as desirable, feasible, important, and credible solutions to 
workplace accidents where workers become seriously or fatally injured?

The Bolman and Deal espoused a four-frame model for assessing essential organizational issues such as leadership and performance, social interactions, and cultural dynamics (Bolman \& Deal, 2013). Narine (2019) used this four-frame model to explore organizational concepts such as safety rules and procedures, organizational policies, technical and technology impact on work, intra-organizational politics amongst other work-related factors, and how these could result in the prevention of workplace accidents, in the United States, where workers can become seriously injured or killed. Narine (2019) conducted a similar study in the Caribbean. The working arrangements of electric power industry organizations in Canada based on responses provided by active practitioners, as experts, to the researcher set questions over four distinct Delphi rounds, was the focus in this particular study.

\section{The DelPhi TeCHNIQUE}

The Delphi technique is ideal for this qualitative study, where participants communicated with the researcher only and remained anonymous to other participants throughout the four different rounds of the study (Dalkey \& Helmer, 1963). Narine (2019) found the Delphi technique suitable for similar studies as this, conducted in the United States and the Caribbean. The researcher's control and maintenance of set pre-conditions that participants agreed to before the study commenced is vital for conducting a successful Delphi research (Linstone \& Turoff, 1975). Participants responded based on their understanding and interpretation of the researcher set questions conducted over four different Delphi rounds.

For the Delphi round 1, participants responded to items, derived by the researcher from earlier studies on workplace accidents, to indicate whether these items contributed to electrical power industry accidents. Participants also provided solutions they felt would assist in the prevention of future accidents. For each item from round 1 where more than $50 \%$ of the participants believed, by selecting a three, four or five in a Likert-type scale, that an item in the round 1 questionnaire was a causal factor in workplace accidents in the electrical power industry, and they provided possible solutions, were kept for consideration in the round 2 . In round 2 , participants indicated whether the solutions from round 1 were feasible and desirable. Items from Round 2 supported by $70 \%$ or more participants selecting a score of four or five on a five-point Likert-type scale qualified for the Delphi round 3: This criterion was valid for the round 3 items that progressed to round 4 . In round 3 , participants indicated whether each questionnaire item was important. In round 4, they indicated whether the solution to the item was credible for each item on the questionnaire (Narine, 2019).

\section{PARTICIPANT SELECTION AND PERMISSION}

For this study, participants came from LinkedIn, a public social media platform. Invitations sent to prospective participants align with the methodology adopted by Narine (2019). Invitees received research pre-conditions via Survey Monkey, with the initial invitation to participate. Invitees became participants upon agreeing to the research pre-conditions. Participants were volunteers who operated as electrical power industry experts in Canada and satisfied the criteria as espoused by Narine (2019). Participants were industry practitioners with ten years or more working experience as a worker, professional, workplace trainer, supervisor, or manager in Canada. Each participant also indicated that they knew of workplace accidents in Canada where electric power industry workers were either seriously injured or killed while doing work. Participants in this study were anonymous to one another. Only the researcher knew the participants.

The Delphi Study occurred over four different rounds. The Survey Monkey facilitated questionnaires for each Delphi round in this study. The deliberate strategy for this survey was that participants' responses went to the researcher from Survey Monkey without any specific identifier to link participants to responses. Fifty-four invitations to invitees throughout Canada resulted in positive responses from twelve individuals from British Columbia, Alberta, Saskatchewan, Manitoba, Ontario, and Newfoundland/Labrador. Nine individuals became participants. None of these individuals were from Newfoundland/Labrador. Table 1 and Table 2 cover the demographic breakdown of the research participants.

Table 1.

\begin{tabular}{|c|c|c|c|c|c|c|}
\hline \multirow{2}{*}{$\begin{array}{c}\text { Average Sevica(Vm) } \\
\text { Paticost: }\end{array}$} & \multirow{2}{*}{$\begin{array}{c}23.7 \\
\mathrm{Yrs} \\
\text { Service }\end{array}$} & \multicolumn{5}{|c|}{ Industry Expe'ence / Operated as } \\
\hline & & Woker & Supevisor & Trainer & Profassional & Mangager \\
\hline$\neq 1$ & 10 & 1 & 0 & 0 & 1 & 0 \\
\hline$\neq 2$ & 33 & 1 & 1 & 1 & 1 & 1 \\
\hline$\neq 3$ & 26 & 0 & 0 & 0 & 1 & 1 \\
\hline$\neq 4$ & 15 & 0 & 0 & 0 & 1 & 0 \\
\hline$\neq 5$ & 33 & 1 & 0 & 1 & 0 & 0 \\
\hline$\neq 5$ & 25 & 1 & 1 & 0 & 0 & 0 \\
\hline$\$ 7$ & 33 & 1 & 1 & 0 & 1 & 0 \\
\hline$\neq 8$ & 21 & 1 & 0 & 0 & 1 & 1 \\
\hline$\neq 9$ & 17 & 0 & 0 & 1 & 1 & 0 \\
\hline \multicolumn{2}{|c|}{ =Paticipants/Work Catagry } & 6 & 3 & 3 & 7 & 3 \\
\hline \multicolumn{7}{|c|}{ AveYo Servica/Particionts } \\
\hline \multicolumn{2}{|c|}{ (Casegry) } & 258 & 303 & 27.7 & 221 & 267 \\
\hline \multicolumn{2}{|l|}{ Number of linizess } & 54 & & & & \\
\hline
\end{tabular}

In this study, the average length of service for participants is 23.7 years. Five participants worked for more than 23.7 years. Three participants for worked 33 years each. None of the participants who began as workers remained at that level for this study. There were three managers whose average electric power industry experience spanned an average of 26.7 years.

Table 2, Detailed Information on Participants

\begin{tabular}{|c|c|}
\hline Participant & Added Demographic Details (Participants) \\
\hline$\# 1$ & Professional/Technical \\
\hline$\# 2$ & $\begin{array}{l}\text { Professional/Technical, Supervisor, Trainer, } \\
\text { Manager/Training, Generation }\end{array}$ \\
\hline$\# 3$ & $\begin{array}{l}\text { Management with responsibility for electrical and other } \\
\text { high-risk or hazardous works, }\end{array}$ \\
\hline \#4 & Professional/Technical \\
\hline \#5 & Operator, Trainer \\
\hline \#6 & foreman, supervisor, live work, work up to $500 \mathrm{kV}$ \\
\hline$\# 7$ & Lineman, supervisor, Professional/Technical \\
\hline \#8 & Operator, Generation Engineer, Manager \\
\hline \#9 & Safety Management \\
\hline
\end{tabular}




\section{RESULTS.}

Table 3 Round One Response

\begin{tabular}{|c|c|c|}
\hline Causal Factor in Electric Power Industry Accidents & $>49.9 \% \mathrm{Y}$ & Remark \\
\hline Q1: Poor Design & $\bar{N}$ & Dropped from study \\
\hline Q2: Management System Flaw & Y & Proceed to Round 2 \\
\hline Q3: Poor Regulatory & & \\
\hline Oversight & $\mathrm{N}$ & Dropped from study \\
\hline $\begin{array}{l}\text { Q4: Poor work ethics; history of wrongdoing that went } \\
\text { unaddressed }\end{array}$ & y & Proceed to Round 2 \\
\hline Q5: Incorrect labeling & $\mathrm{N}$ & Dropped from study \\
\hline Q6: Medical and other personal issues & Y & Proceed to Round 2 \\
\hline Q7: Grounding, earthing failures / errors & Y & Proceed to Round 2 \\
\hline Q8: Ineffective and inefficient maintenance & y & Proceed to Round 2 \\
\hline Q9: Animals / living organisms & N & Dropped from study \\
\hline Q10: Hazardous worksite conditions & Y & Proceed to Round 2 \\
\hline Q11: Unplanned events & y & Proceed to Round 2 \\
\hline Q12: Inappropriate work methods & Y & Proceed to Round 2 \\
\hline Q13: Stakeholder demands & Y & Proceed to Round 2 \\
\hline Q14: Poor judgment by individuals or work crews & y & Proceed to Round 2 \\
\hline Q15: Poor attitude and or behavior by individuals or work crews & Y & Proceed to Round 2 \\
\hline Q16: Ineffective or no workplace training & Y & Proceed to Round 2 \\
\hline Q17: Poor supervision & y & Proceed to Round 2 \\
\hline Q18: Work planning & Y & Proceed to Round 2 \\
\hline Q19: Management priorities & y & Proceed to Round 2 \\
\hline Q20: Poor team communication & y & Proceed to Round 2 \\
\hline Q21: Willful disregard for safety rules & Y & Proceed to Round 2 \\
\hline Q22: Permit to work violations & y & Proceed to Round 2 \\
\hline Q23: Lock-out tag-out non-compliance & Y & Proceed to Round 2 \\
\hline Q24: Organizational safety culture & y & Proceed to Round 2 \\
\hline Q25: Individual risk taking and negligence & y & Proceed to Round 2 \\
\hline Q26: Equipment failure & Y & Proceed to Round 2 \\
\hline Q27: Procedural error & y & Proceed to Round 2 \\
\hline Q28: Poor management oversight & y & Proceed to Round 2 \\
\hline Q29: Poor quality material & N & Dropped from study \\
\hline Q30: Non-use or personal protective equipment & Y & Proceed to Round 2 \\
\hline
\end{tabular}

The round 1 questionnaire contained 30 researcher set items developed from previous research work. Participants' response was on their belief that the item for each question was an accident causing factor in the Canadian electric power industry. Less than $50 \%$ of participants believed that five items were causal factors in the accidents occurring in Canada. These were Poor Design, Poor Regulatory Oversight, Incorrect Labeling, Animals/living organisms, and Poor Quality Material, removed for round 2 consideration.

Another five items dropped from the study after round 2, Ineffective and inefficient maintenance, Unplanned events, Wilful disregard for safety rules, Lock-out tag-out non-compliance, and Equipment failure as less than $70 \%$ of participants felt that solutions to these items were feasible and desirable and they would not result in accident prevention. All of the twenty other items progressed through round 3 or round 4 as more than $70 \%$ of the responses showed that these solutions were important, and participants were confident that these could lead to accident prevention in the Canadian electric power industry.

\section{Participant-provided Solutions}

- Item2 Management System Flaw: Solution S2 Safety Management Systems generally reference against set international standards uniquely applied for the particular organization and the work functions and activities at that organization. It is this unique reshaping that can, at times, be sub-optimal and the issue of contention. These issues can involve unintended issues such as inappropriate supervision leading to human errors, fatigue, routine, and intentional cutting of corners. In other instances, issues can surround documentation when equipment changes occur without a review of work procedures or workers receiving appropriate training on the new devices or systems. Organizational leadership shall frequently (possibly semi-annual) audit the safety management system and require management action regarding non-compliance or any other matter raised audit findings. Managers shall have their performance reviewed on a semi-annual basis with workplace safety performance equally ranked as financial and production criteria.

- Item 4 Poor work ethics; history of wrongdoing that went unaddressed: S4: Supervisors and managers must accept that there is a history of wrongdoing that went unaddressed and that organizational requirements are that this is intolerable, regardless of the individual or individuals involved. An intolerance for wrongdoing is necessary for accident prevention and safe work. Workers' behavior is shaped by wrongdoing if there is no strict compliance with work rules and procedures. Organizational leaders shall dismiss managers and supervisors if they commit wrongdoing contrary to existing work rules and procedures as well as for not addressing worker wrongdoing.

- Item 6 Medical and other personal issues: S6: Generally, employees with any medical or personal issues have a responsibility to disclose any restrictions as a result of that issue. Workplace training must be done for individuals to recognize and treat with possible cases of this type. All individuals at work shall actively encourage others, as per workplace training, to seek appropriate professional assistance. Workers must recognize that their safety, as well as that of their fellow workers, are at stake if problems exist where they, as individuals may not be able to perform complex and challenging work tasks. All individuals at work must lookout for any possible indication that all is not well with work crew members and are actively encouraged to respect that while making supervisors aware. Supervisors must be trained, proven competent, and shall address any situation communicated in this regard.

- Item 7 Grounding, earthing failures / errors: S7: Grounding is a work activity that is performed by individuals who receive specific and detailed training on how to perform this task safely. The likelihood of serious and fatal injuries are real when grounding or earthing errors occur. Organizational leadership, managers, and supervisors must demand strict compliance with work rules and procedures regarding grounding and earthing. Workers must continuously remember that their lives are at stake for grounding and earthing not correctly done. No work shall be done on systems where grounding or earthing were required and not done or if not done as prescribed. All defaulting parties to grounding and earthing breaches shall be severely reprimanded and even dismissed from the organization.

- Item 10 Hazardous worksite conditions: S10: All individuals at work shall follow work-related rules and procedures that are organizational approved. Workers have a right to refuse to do work if they believe that it is dangerous and cannot accomplish it safely. Work planners must be trained and competent to ensure that work plans align with safe work as a top requirement and that risks 
due to identified hazards can become appropriately mitigated. Workers on job sites must ensure that they fully understand the tasks, they can perform such tasks, and they can ensure that housekeeping at the worksite is such that items of materials and tools do not add other hazards to the worksite to make it even more hazardous. Supervisors and workers must communicate with one another and be sure that all hazards are recognized, risk-assessed, and mitigated before work commences and for the duration of work tasks. If during work, new hazards arise, then all work must be stopped if these hazards can breach the existing barriers in place to protect workers from becoming injured.

- Item 12 Inappropriate work methods: S12: Work rules and procedures have been proven over years of consistent practice and verified by practitioners with extensive experience in varied work conditions. It is still possible, however, that workers may recognize situations for work activities in places and conditions where existing work rules do not adequately cover. Work planners and supervisors must ensure and develop work tasks by following existing work rules and procedures. Workers and work crews must evaluate worksites before commencing work tasks to confirm that work plans are appropriate and can reasonably do it. Any deviation from set work procedures shall be brought to the supervisor's attention before any work task commencing. Upon being informed, the supervisor and crew will review the work plans, confirm if the job can proceed, and safely perform work under the purview of the supervisor. The supervisor must then follow-up with managers for work methods to be reviewed and revised to cover for situations not adequately addressed in existing work rules and procedures. Worker re-training shall follow afterward.

- Item 13 Stakeholder Demands: S13: Supervisors must be aware of work that can be customer and stakeholder sensitive. That, as a factor, must be considered during work planning and while performing the actual tasks. Managers must coordinate with stakeholders so that realistic expectations are known to clients as well as working crews and supervisors. Workers shall conduct work exercises in ways to facilitate changes to work scope even if that request comes after the initial task commences. That change-request makes supervisor involvement and manager-supervisor communication critical and vital if work tasks are to be done in an error-free and safe manner while still satisfying original and changing stakeholder requests. All individuals at work must receive training and be proven competent to work in this environment. Organizational leadership must support management and workers so that stakeholder demands do not escalate into challenging to manage situations: No one shall do work in an unsafe manner. No stakeholder request will supersede safe work instructions and practices.

- Item 14 Poor judgment by individuals or work crews: S14: To err is human, but at work, especially in dangerous conditions and situations, individuals must not err. The consequences of erring on safety-sensitive and dangerous work exercises can be the difference between successful work accomplishments and worker injuries or fatalities. Supervisors must ensure that workers are capable of recognizing hazards, performing risk assessments, and taking appropriate measures to mitigate the risks. Inadequate risk assessment leads to inappropriate and many times, unsafe work methods where individuals become injured or killed, and equipment or process failure occurs. No individual at work shall proceed with work tasks if unsure about how to best perform the ask even if by following accepted organizational set work rules and procedures. In cases where workers believe procedures or rules are insufficient, the workers shall invoke supervisor and manager involvement so that the relevant reviews can occur.

- Item 15 Poor attitude and or behavior by individuals or work crews: S15: Individuals at work must understand that poor attitudes and behavior can lead to their removal from jobs and even their dismissal from the organization. Managers and supervisors must ensure that their actions are fair, consistent, and in line with organizational rules and procedures. That way, they will not contribute to situations or circumstances where individual workers or groups of workers will likely exhibit poor attitudes or behavior. Poor attitudes and behavior can significantly reduce abilities and opportunities for successful organizational outcomes and customer satisfaction. Poor attitude leads to poor habits and practices. Those, in turn, lead to a rise in the risk of incidents and ones with greater severity. It is incumbent on all individuals at work to strictly comply with organizational codes, set rules, and procedures regarding individual behavior and attitudes.

- Item 16 Ineffective or no workplace training: S16: Training can be a significant factor if workers are thrust into a work environment to perform tasks without first being trained on how to perform that task. The consequences of this can translate to incidents where individuals are seriously injured or killed, with equipment damaged beyond usefulness, and worker confidence and trust in organizational processes are lost. Managers and supervisors must only allow individuals to work on tasks that they are trained and certified as competent. Supervisors shall exhaust all avenues to have suitably experienced and knowledgeable individuals with work crews so that all at work can effectively share learning on the job for organizational success. No one at work shall attempt to work where the necessary training and knowledge is unavailable at the time when performing the task.

- Item 17 Poor supervision: S17: Supervision is paramount for safe work and accident prevention. Although workers should be capable of independently performing their work, supervision provides for the high-level performance monitoring and compliance that is often necessary to help the worker to see something that they missed. Supervision is also a compliance factor in workers' adherence to organizational-approved safety practices and protocol. Organizational leadership must, therefore, review supervisor requirements and train prospective candidates over a suitable period before assessing the candidates to confirm readiness for assuming supervisory roles. No individual should become a supervisor without rigorous training and organizational coaching. Individuals who already are supervisors shall be re-oriented and supported by managers and organizational leadership to function as the organization would expect. Supervisors shall be 


\section{International Journal of Engineering and Technical Research (IJETR) \\ ISSN: 2321-0869 (O) 2454-4698 (P) Volume-9, Issue-12, December 2019}

removed from this role if they are deemed unsuitable. Suitability must reference known criteria; set by organizational leadership.

- Item 18 Work planning: S18: Safe work planning protocols are quite thorough in the utility sector. Failing to plan is planning to fail. Managers and supervisors must know that a work plan is only useful when everyone knows the work strategy and pertinent details about the task. If these are not communicated effectively to all at work, then individuals performing work will not know what to do and their part in the exercise. When work is unplanned, possible hazards can go unnoticed and go unaddressed. These represent lost opportunities to mitigate danger and for individuals at work to remain safe. Managers and supervisors must ensure that work planning is effective and efficient for the best organizational outcomes.

- Item 19 Management Priorities: S19: Management must be explicit in its endorsement and support of Safety Management as safe work is unlikely without a consistent message and backing. Without an established management priority, workers will not be confident that there will be no recrimination from supervisors when stopping jobs, if not safe, and that customers will fully appreciate and understand that the job cannot proceed otherwise. Workers must be genuine and perform work when it can be done and not use workplace safety as an excuse to delay work. For workers and supervisors to converge on a shared understanding of work and the performance of work, managers and leaders must ensure that arrangements are set for individuals at work to discuss concerns in a non-adversarial manner and for addressing issues raised regarding work processes, procedures and arrangements openly and transparently. Under no situation should a willful disregard for work rules and procedures be preferred over the opportunity for work discussion and successful outcomes. Workers not following managers and supervisors guidance under these circumstances will have an opportunity to highlight their concerns to a select team of individuals specially selected to address matters such as these. Managers and supervisors must retain the ability to move errant individuals from work until issues raised are considered and adjudicated by the select team.

- Item 20 Poor team communication: S20: Communication is a critical factor in the workplace. Miscommunication can lead to incidents with severe consequences. Organizational Leadership, managers, and supervisors must emphasize that no work shall be done without all individuals at work, fully understanding their role in the job, and how that can impact on others. No team leader must assume that individual employees understand the task without confirming that they do. This confirmation shall be the on-site registration of worksite conversation included in the toolbox talk documentation. This registration is an essential indicator that individuals at work understand their roles and the implications of not thoroughly discussing the work.

- Item 22 Permit to work violations: S22: Permits to Work procedures and systems are specific work practiced by individuals who are specially trained, proven capable, and competent, and are authorized to perform that work in the strictest of work arrangements. Therefore, organizational leaders, managers, and supervisors must recognize that Permit to Work violations is a symptom of a poorly functioning safety management system. Managers and supervisors must consistently demand full compliance and dismiss offenders. Organizational leadership must support management in this regard: a zero-tolerance for Permit to Work violations.

- Item 24 Organizational safety culture: S24: Safety culture is more than an understanding of an organizational health and safety policy, managed systems, safety code, work rules, and procedures. It more reflects work practices that support individual and group knowledge, beliefs, attitudes, and behavior. A good safety culture depends on consistent, meaningful, and genuine involvement of people for best results and safe outcomes; Organizational leadership must, therefore, accept and exercise responsibility for encouraging and realizing the best organizational safety culture. Nothing less will realize the safest workplace culture.

- Item 25 Individual risk-taking and negligence: S25: Organizational leadership and management must expound that each individual at work is obligated to follow organizational set rules and procedures. Leaders must create and promote that culture, and workers must also be willing to remain safe as a necessary condition of employment. Workers shall have supervision while performing dangerous tasks with supervisors being empowered to stop work and to remove errant individuals. Managers must support supervisors if or when they remove workers from worksites. Individuals working alone must have technical systems and or technologies for remaining in contact with other competent persons while performing work.

- Item 27 Procedural error: S27: Organizational reference shall be that procedural error would not occur unless particular conditions exist. These include a deliberate attempt not to follow set organizational rules and work procedures, a misunderstanding of work rules and procedures, a poor interpretation of work rules and procedures, poorly implemented work procedures. In each of these cases or situations, supervisors and managers have the onerous responsibility of confirming that workers are trained, proven capable, competent, and adequately supervised by individuals with appropriate knowledge and ability to recognize when work procedures are incorrectly applied. Workers must also be encouraged to ask questions when they are unclear about organizational rules and work procedures or if situations exist that they are unaccustomed.

- Item 28 Poor management oversight: S28: Leadership must consistently require strict management and supervisory compliance with organizational rules and procedures and give a clear indication that failure will result in dismissal: an example that leadership must set. Managers must support supervisors' implementation of work rules and procedures without unfairly stymieing union agreements.

- Item 30 Non-use or personal protective equipment: S30: Personal protective equipment must be available for workers to use at all times. Workers shall receive training on how to use, maintain, and store PPE. There shall be adequate storage space available for workers to keep PPE, 
when not in use on worksites. Supervisors shall remove errant workers from worksites and initiate actions to counsel or dismiss Individuals who willfully do not use PPE from the organization if that becomes necessary.

Table 4 shows the desirable, feasible, important, and credible solutions for the entire study based on the overall responses of participants and which can lead to electric power industry accident prevention.

Table 4,

\begin{tabular}{|c|c|c|c|}
\hline & $\begin{array}{c}\text { Desirable and Feasible } \\
\text { Round } 2\end{array}$ & $\begin{array}{l}\text { Important } \\
\text { Round } 3\end{array}$ & $\begin{array}{c}\text { Confidence } \\
\text { Round } 4\end{array}$ \\
\hline S1 & Dropped from study & Drooped from study & Dropoed from study \\
\hline$\$ 2$ & 7 & 8 & 7 \\
\hline$\$ 3$ & Dropped fromstudy & Dropped from study & Dropoed from study \\
\hline$\$ 4$ & 8 & 9 & 8 \\
\hline$\$ 5$ & Dropped fromstudy & Drooped from study & Dropped from study \\
\hline$\$ 6$ & 7 & 7 & 5 \\
\hline$\$ 7$ & 8 & 8 & 8 \\
\hline 58 & Not D/F & Droppedafter $R 2$ & Dropped from study \\
\hline$\$ 9$ & Dropped fromstudy & Dropped from study & Dropoed from study \\
\hline$\$ 10$ & 9 & 9 & 8 \\
\hline \$11 & Not $D / F$ & Droppedafter $R 2$ & Dropoed from study \\
\hline$\$ 12$ & 8 & 7 & 8 \\
\hline$\$ 13$ & 8 & 8 & 5 \\
\hline$\$ 14$ & 9 & 8 & 8 \\
\hline$\$ 15$ & $g$ & 8 & 8 \\
\hline$\$ 16$ & 8 & 9 & 9 \\
\hline$\$ 17$ & 8 & 8 & 9 \\
\hline$\$ 18$ & 9 & 9 & 9 \\
\hline$\$ 19$ & 7 & 8 & 7 \\
\hline$\$ 20$ & 9 & 9 & 8 \\
\hline$\$ 21$ & Not $D / F$ & Dropoedafter $R 2$ & Dropoed from study \\
\hline$\$ 22$ & 7 & 8 & 8 \\
\hline$\$ 23$ & Not $D / F$ & Droppedafter $R 2$ & Dropoed from study \\
\hline$\$ 24$ & 9 & 8 & 8 \\
\hline$\$ 25$ & 7 & 7 & 7 \\
\hline$\$ 26$ & Not D/F & Droppedafter $R 2$ & Dropoed from study \\
\hline$\$ 27$ & 8 & 9 & 9 \\
\hline$\$ 28$ & 7 & 8 & 8 \\
\hline$\$ 29$ & Dropped from study & Dropped from study & Dropped from study \\
\hline$\$ 30$ & 7 & 8 & 8 \\
\hline
\end{tabular}

\section{DISCUSSION}

The thirty items included in the round 1 questionnaire were from previous studies as factors that contribute to accidents in the workplace. Participants agreed that twenty-five of these items were factors in the Canadian electric power industry accident-experience. Solutions suggested by participants to these twenty-five items formed the input to the round 2 questionnaire. Participants only supported twenty solution-items from the round 2 questionnaire as feasible and desirable, which proceeded to round 3 . All of the round 3 items remained for consideration in round 4.

Considering Participants support, actual responses, and the study significance.

One response for the Issue on Management System Flaw was, "If there are gaps and loopholes, these will often get exploited rather than fixed. These gaps are sometimes all it takes to enable a serious or fatal incident." Another response was, "we have found that many workers circumvent the rules to get the job done. Management turns a blind eye as the work is being completed with no incidents."

One response for the Issue on Poor work ethics; history of wrongdoing that went unaddressed was, "Culture, and a get it done attitude and timelines can lead to wrongdoings." Another response was, "If the person's belief does not align with the corporate safety culture, then they will generally choose to follow their own preferences. If this does not get addressed, then the worker will believe that they have an unofficial approval from management and thus will reinforce their behaviour and attitude to the proper safety measures." One response for the Issue on Medical and other personal issues was, "Yes drugs are more prevalent these days. When people are not in the moment, this can definitely lead to a serious incident."

For the Issue on Grounding, earthing failures/errors, one participant suggested, "I have first-hand experience in this one, having had an incident reported to me while on shift. Grounding procedures were not followed in the field, and a death occurred as a result. Grounding is one of the safeguards that workers rely on, and if not done properly or if they are defective, the risk of an incident with severe consequences becomes greatly elevated."

For the Issue on Hazardous worksite conditions, one participant suggested, "Our power lines run through extremely varied and challenging terrain and are not always positioned with access at the front of mind." Another response was, "The desire in performing any job is to eliminate as many or all hazards as possible. When performing a job with uncontrolled or numerous hazards present, the likelihood of an incident rises. The severity of an incident also rises with the increase of potential energy present in the hazard. The presence of the hazard also distracts the worker from performing the job and gives rise to incorrect work being completed."

For the Issue on Inappropriate work methods, one participant suggested, "People often seem to think they were smarter than the generations of line workers who developed the techniques we use. It is very rare they are right. Additionally, not being properly equipped leads to workers getting creative and causing themselves and others issues." Another response was, "When staff deviates from a procedure in order to get the job done, they put themselves and coworkers in danger. Staff needs to stop work report the issue to the supervisor and work together to come up with a solution."

For the Issue on Stakeholder Demands, one participant suggested, "This is an interesting one as I would argue that internal pressure drives us to a certain behaviour. Again, very difficult to validate in many instances, but subtle or overt pressure from the valued customer/boss/coworker/internal pressures will take an employee to a place of cutting-a-corner. I have seen this first hand in my experience with the utility sector. I believe behind every serious incident, and there is a pattern of corners being cut antecedents."

For the Issue on Poor judgment by individuals or work crews, one participant suggested, "Mistakes happen, and sometimes a poor choice can translate that mistake into a full-blown incident. Often time, choices are made with good intent; however, when coupled with poor or impaired judgment, it could lead to a serious incident." Another response was "Inadequate supervision due to poor judging of a crew's capability." 
For the Issue on Poor attitude and or behavior by individuals or work crews, one participant suggested, "There is always going to be that crew member who requires special attention." Another response was, "It is a manager/supervisor's responsibility to deal with attitude issues and make decisions on who and who is not on a work crew."

For the Issue on Ineffective or no workplace training, one participant suggested, "We always blame training. Often though, an incident does occur because a worker's skill set was not at the level needed to perform the work." Another response was "Ineffective, or lack of workplace training is a symptom of poor Safety Management plan implementation." For the Issue on Poor supervision, one participant suggested, "Complexity of job, crews combined experience with the task and crew size are all factors." Another response was, "If the supervisor is not respected, treats his/her staff poorly, they can significantly contribute to serious incidents."

For the Issue on Work planning, one participant suggested, " $A$ good plan will help create a streamlined process to complete work, will help eliminate hazards and will create an atmosphere where the job will be completed successfully. If the plan is not correctly executed, then the risk of incident greatly rises, as well as severity."

For the Issue on Management Priorities, one participant For the Issue on Management Priorities, one participant suggested, "A company may preach safety on one hand, but may try to force a compromise in the light of increased efficiencies or profits. Sadly, there is the ongoing tension of productivity and working to that ultimate level of safety. I believe there are many current and active behaviours and antecedents as a result of that tension. Do the job done on time and budget while keeping the customer happy is a dynamic that imposes itself and work and safe work practices."

For the Issue on Poor team communication, one participant suggested, "Probably the most critical components of an effective team is effective communication. You may be the smartest, best-trained individual with a brilliant and effective plan; however, if you cannot or do not communicate this plan, then your plan is garbage." Another response was, "Poor team comms can lead to lack of understanding and mismanagement of risk. "

For the Issue on Permit to work violations, one participant suggested, "Work permits are the vehicle used to properly plan a job. If violations are made during this process, then the likelihood of a proper plan is low. Not having a proper plan will often lead to gaps that can enable an incident to occur." Another response was, "As a work protection code coordinator/monitor in a previous work experience, there were many code violations that needed to be addressed."

For the Issue on Organizational safety culture, one participant suggested, "If the company does not care, then why should I? Leadership comes from the top. If a culture is not important to leadership, then it will not be important to the workers either. A lack of leadership creates an atmosphere of risk-taking and rule-breaking." Another response was, "Nobody comes to work wanting to get hurt, and no supervisor/manager wishes their staff to be hurt. But we need to look at our Just Culture to see if we are looking at people in a different light. Instead of asking what did he/she do wrong, we should ask what did we do wrong to fail them."

For the Issue on Individual risk-taking and negligence, one participant suggested, "I believe this does occur. When reviewing the many serious incidents, there is a step or barrier where a cognitive decision was made to work through or to ignore a barrier. I will say that this would be symptomatic of a lesser engaged work safety culture." "Individual negligence is a symptom of poorly implemented and monitored Safety Management system."

For the Issue on Procedural error, one participant suggested, "Procedures are meant to create an atmosphere of success. Not following a procedure can often allow critical steps to be missed, that would have controlled a hazard that can lead to an incident." Another response was, "Relying on procedures instead of designing hazards out of the system is an issue."

For the Issue on Poor management oversight, one participant suggested, "If management does not follow up and encouragelenforce safety compliance, then workers will not see it as important too." Another response was, "Oversight is a big word in this question, but I would suggest that if oversight speaks to culture, that absolutely yes. We are talking about development of the procedures, I believe this process is very robust with few holes in the sectors for which I have worked. A lot of time and effort goes into preparing, reviewing, testing work procedures and processes that, if not managed and supervised properly, they would not factor."

For the Issue on Non-use or personal protective equipment, one participant suggested, "A person's non-compliance with a safety procedure can be a cause of accident although a Safety Management system should strive to prevent a person's non-compliance through training, checks and balances and other affirmative steps." Another response was, "PPE is the final barrier in the electricity industry. If worn/used correctly, it prevents serious injuries from occurring. Removing your final barrier is only asking for trouble."

\section{CONCLUSION}

This study represents an opportunity to understand the reasons why workplace accidents are happening in the Canadian electric power industry and what can be done to prevent future accidents from occurring. The study is an opportunity for practitioners to review and to join into a broader discussion whereby individuals with knowledge and experience can add their views and appreciation for the electric power industry to evolve to where no worker will become injured or killed at work.

There are twenty different accident causing factors identified in this study, with suggested solutions. Canadian electric power industry leaders and managers may use these results to realize accident-free workplace, superior organizational performance outcomes, and to prevent serious worker injuries or fatalities.

\section{REFERENCES:}

[1] Aboagye-Nimo, E., Raiden, A., King, A. and Tietze, S., 2015. Using tacit knowledge in training and accident prevention. Proceedings of Institution of Civil Engineers: Management, Procurement and Law, 168(5), pp.232-240. Available at: http://dx.doi.org/10.1680/mpal.1400027.

[2] Bolman, L. G., \& Deal, T. E., 2013. Reframing organizations: Artistry, choice, and leadership (5th ed.). San Francisco, CA: Jossey-Bass.

[3] CASB (1992) Aviation occurrence report Arrow Air Inc. Douglas DC-8-63 N950JW Gander International Airport, Newfoundland December 1985 Report Number 85-H50902. The Canadian Aviation Safety Board Retrieved from http://flightopsresearch.org/data/files/arrow1285.pdf 
[4] Cashman, R. (2019). PD: Eversource subcontractor killed in Middletown on Sunday. WFSB (Meredith Corporation). Retrieved from

https://www.wfsb.com/news/pd-eversourcesubcontractor-killed-in-m iddletown-on-sunday/article_c9dc648c-1cfc-11e9-999d3bd82366bd a7.html

[5] Dalkey, N., \& Helmer, O., 1963. An experimental application of the Delphi method to the use of experts. Management Science, 9(3), pp 458-467. Available at: http://dx.doi.org/10.1287/mnsc.9.3.458

[6] Laberge, M., MacEachen, E., \& Calvet, B., 2014. Why are occupational health and safety training approaches not effective? Understanding young worker learning processes using an ergonomic lens. Safety Science, 68, pp 250-257. Available at: http://dx.doi.org/10.1016/j.ssci.2014.04.012

[7] Labib, A. (2015). Learning (and unlearning) from failures: 30 years on from Bhopal to Fukushima an analysis through reliability engineering techniques. Process Safety and Environmental Protection, 97, 80-90. doi: 10.1016/j.psep.2015.03.008

[8] Linstone, H. A., \& Turoff, M., 1975. The Delphi method: Techniques and applications. Reading, MA: Addison-Wesley.

[9] McCabe, P. 2019. Update: Hydro One Forestry worker killed in workplace accident near Haliburton. Retrieved from https://www.myhaliburtonnow.com/33296/one-person-deceased-foll owing-industrial-accident/

[10] Manuele, F. A., 2014. Incident investigation our methods are flawed. Professional Safety, 59(10), 34. Available at: http://www.asse.org

[11] Murata, A. (2017). Cultural difference and cognitive biases as a trigger of critical crashes or disasters - evidence from case studies of human factors analysis. Journal of Behavioral and Brain Science, 7(09), 399. doi:10.4236/jbbs.2017.79029

[12] Moshansky, V. P. (1992). Commission of inquiry into the Air Ontario accident at Dryden, Ontario (Final Report, Vol. 1-4). Ottawa, ON: Ministry of Supply and Services, Canada Retrieved from https://lessonslearned.faa.gov/Fokker/000347.pdf

[13] Narine, G., 2019. Causes and prevention of electric power industry accidents: A Delphi study. Retrieved from https://scholarworks. waldenu.edu/cgi/viewcontent.cgi?article $=8767$ \&context $=$ dissertations

[14] NTSB. 2018. ERA19FA035 Aircraft: Aerospatiale AS 355F2, registration: N372CA. Retrieved from https://www.ntsb.gov/_layouts/ntsb.aviation/brief.aspx?ev_id=2018 $1030 \times 81557$

[15] NTSB, 1993. Aircraft accident report, takeoff stall in icing conditions, USAir Flight 405, Fokker F-28, N485US, LaGuardia Airport, Flushing, New York. Retrieved from https://www.ntsb.gov/Pages/default.aspx

[16] Patton, J. 2018. Forestry worker killed by falling tree during storm, high winds in Greater Toronto Area. Retrieved from https://globalnews.ca/news/4188523/maintenance-worker-died-tree-f alls-storm-milton/

[17] Probst, T. M. (2015). Organizational safety climate and supervisor safety enforcement: Multilevel explorations of the causes of accident underreporting. Journal of Applied Psychology, 100(6), 1899. doi: 10.1037/a0039195

[18] TSB. (2017) Air transportation safety investigation A1700264. Retrieved

from http://tsb-bst.gc.ca/eng/enquetes-investigations/aviation/2017/A17O 0264/A17O0264.html

[19] Tucker, S., Ogunfowora, B., \& Ehr, D., 2016. Safety in the c-suite: How chief executive officers influence organizational safety climate and employee injuries. Journal of Applied Psychology, 101(9), 1228 Available at: http://dx.doi.org/10.1037/ap10000116

[20] Volberg, V., Fordyce, T., Leonhard, M., Mezei, G., Vergara, X., \& Krishen, L. (2017). Injuries among electric power industry workers, 1995-2013. Journal of Safety Research, 60, 9- 16. doi 10.1016/j.jsr.2016.11.001

Ganesh Narine, Ph.D., MPhil, MSc (Eng), BSc (Eng), is an electric industry engineer and manager with more than 30 years of experience in Generation, Transmission, Distribution, Engineering, Management, and Executive Management in the Caribbean (Trinidad and Tobago). He is now a Senior Manager at one of the largest electric utility companies in Canada. His research interest is in electric industry performance improvement and accident prevention. 